\title{
New dryolestidan mammal from the Hauterivian-Barremian transition of the Iberian Peninsula
}

Gloria Cuenca-Bescós, Ainara Badiola, Josė I.Canudo, Josė M. Gasca, and Miguel Moreno-Azanza Acta Palaeontologica Polonica 56 (2), 2011: 257-267 doi: http://dx.doi.org/10.4202/app.2009.0157

Crusafontia amoae sp. nov. (Dryolestida, Stem Cladotheria) is represented by two isolated upper molars (M4 or M5 and M6 or M7) from the terminal Hauterivian-basal Barremian (Early Cretaceous) of the El Castellar Formation (Galve, Spain). The molars have a deep ectoflexus, a distinct metacone, a continuous metacrista, and an antero-lingually placed paracone. They differ from the molars of the other species of the genus, Crusafontia cuencana , by their larger size, by their outsized parastyle, by the pointed lingual slope of the paracone, their more symmetrical appearance with a deep ectoflexus in occlusal view, and the well-developed metacone. Revision of three isolated teeth previously attributed to Crusafontia cuencana suggests that instead of being upper premolars belonging to Crusafontia cuencana they in fact belong to Pocamus pepelui, of the stem cladotherian superorder Zatheria, probably "peramuran". As such, the stem Cladotheria record from the Early Cretaceous of the Iberian Peninsula is composed of two dryolestids (Crusafontia amoae and Crusafontia cuencana) and one zatherian (Pocamus pepelui).

Key words: Mammalia, Cladotheria, Dryolestida, Crusafontia, systematics, Cretaceous, Iberian Peninsula.

Gloria Cuenca-Bescós [cuencag@unizar.es], Ainara Badiola [abadiola@unizar.es], José I. Canudo [jicanudo@unizar.es], José M. Gasca [gascajm@unizar.es], and Miguel Moreno-Azanza [mmazanza@unizar.es], Grupo Aragosaurus-IUCA, Paleontología, Facultad de Ciencias, C/ Pedro Cerbuna 12, Universidad de Zaragoza, 50009 Zaragoza, Spain.

This is an open-access article distributed under the terms of the Creative Commons Attribution License (for details please see creativecommons.org), which permits unrestricted use, distribution, and reproduction in any medium, provided the original author and source are credited. 
For 5 Full text (591.6 kB) 